\title{
Heart transplant after profoundly extended ambulatory central venoarterial extracorporeal membrane oxygenation
}

\author{
Yasuhiro Shudo, MD, PhD, Hanjay Wang, MD, Richard V. Ha, MD, Anna D. Hayes, PA-C, and
}

Y. Joseph Woo, MD, Stanford, Calif

\author{
From the Department of Cardiothoracic Surgery, Stanford University School of Medicine, Stanford, Calif. \\ Disclosures: Authors have nothing to disclose with regard to commercial support. \\ Received for publication Oct 31, 2017; revisions received Dec 19, 2017; accepted for publication Feb 4, 2018; \\ available ahead of print March 22, 2018. \\ Address for reprints: Y. Joseph Woo, MD, 300 Pasteur Dr, Falk Cardiovascular Research Center, Stanford Uni- \\ versity School of Medicine, Stanford, CA 94305 (E-mail: joswoo@stanford.edu). \\ J Thorac Cardiovasc Surg 2018;156:e7-9 \\ $0022-5223 / \$ 36.00$ \\ Copyright (C) 2018 by The American Association for Thoracic Surgery \\ https://doi.org/10.1016/j.jtcvs.2018.02.001
}

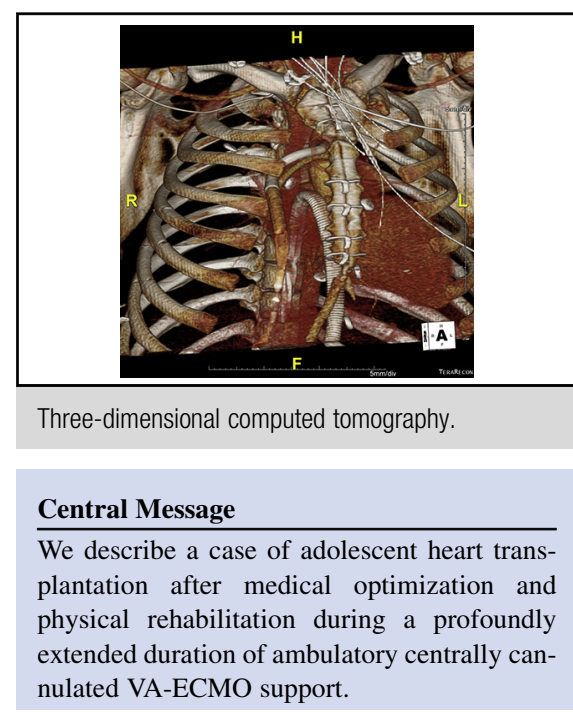

See Editorial Commentary page e11.
Extracorporeal membrane oxygenation (ECMO) is a versatile mechanical circulatory support technique that may be used as salvage therapy for patients with refractory cardiorespiratory failure in the acute setting, or as a bridge to definitive management in the extended term. Ambulatory venovenous ECMO may help optimize the condition of patients with respiratory failure for lung transplantation by allowing physical therapy and preventing deconditioning. ${ }^{1}$ Experience with ambulatory venoarterial ECMO (VAECMO) as a bridging strategy for heart transplantation, however, is less common. Here we describe a case of successful heart transplantation in an adolescent patient after medical optimization and physical rehabilitation during a profoundly extended duration of ambulatory, centrally cannulated VA-ECMO support.

\section{CASE REPORT}

A 17 -year-old boy with a body mass index of $43.9 \mathrm{~kg} / \mathrm{m}^{2}$ and idiopathic cardiomyopathy was initially admitted to a local medical facility with acute heart failure requiring milrinone infusion $(0.25 \mu \mathrm{g} / \mathrm{kg} / \mathrm{min})$. Echocardiography revealed biventricular dysfunction with an ejection fraction of $20 \%$, and a severely dilated left ventricle (LV) with an end-diastolic diameter of $8.0 \mathrm{~cm}$. On hospital day 8 , refractory cardiogenic shock developed after an episode of ventricular tachycardia, and percutaneous VA-ECMO support was initiated (right femoral artery, $21 \mathrm{~F}$ Medtronic BioMedicus cannula; right femoral vein, 23F Medtronic BioMedicus cannula; Medtronic Inc, Minneapolis, Minn). Normal sinus rhythm was restored by antiarrhythmic drug therapy without a need for cardioversion. The next day, the patient was transferred to our hospital for further management. For anticoagulation, a heparin infusion was started to achieve an activated clotting time of 160 to 180 seconds.

On day 3 of ECMO, an Impella ventricular assist device (Abiomed Inc, Danvers, Mass) was placed through the left femoral artery for LV decompression at $2.5 \mathrm{~L} / \mathrm{min}$, allowing the patient to receive peripheral ECMO support of $4.3 \mathrm{~L} /$ min. The postprocedure course, however, was complicated by severe hemolysis (hemoglobin of $7.2 \mathrm{~g} / \mathrm{dL}$ ), liver injury (total bilirubin of $7.9 \mathrm{mg} / \mathrm{dL}$ ), and acute renal failure (creatinine of $3.26 \mathrm{mg} / \mathrm{dL}$ ) necessitating continuous renal replacement therapy. The next day, the patient was taken to the operating room for Impella removal and conversion to central VA-ECMO through a median sternotomy to ensure sufficient support (ascending aorta, 22F Medtronic EOPA cannula; right atrium, 34/38F Medtronic VC2 cannula). Cannula selection was determined by the patient's body surface area $\left(2.66 \mathrm{~m}^{2}\right)$, as well as by the desired ECMO flow $(>5.0 \mathrm{~L} / \mathrm{min})$. In addition, a $20 \mathrm{~F} \mathrm{LV}$ venting catheter was placed through the right upper pulmonary vein, avoiding unnecessary direct manipulation of the LV. Each cannula or catheter was secured to its respective site on the heart with 2 circumferentially placed, pledgeted 4-0 polypropylene purse-string sutures, each reinforced 
with a tightened tourniquet. The aortic cannula and LV vent were tunneled through the chest wall through the third intercostal space, whereas the venous cannula was tunneled through the subxiphoid space. This allowed the sternotomy to be closed primarily (Figure 1 and Video 1). Each cannula or catheter was anchored to the skin at its exit site with a size 0 horizontal mattress suture, and the external portion of each cannula or catheter was further secured with 5 additional sutures tied $1 \mathrm{~cm}$ above the skin and spaced $3 \mathrm{~cm}$ apart, progressing distally from the exit site of the cannula or catheter. Finally, Tegederm (3M, St Paul, Minn) dressings were placed over the length of the cannula or catheter, and the exit sites and skin underneath the cannulas were meticulously cleaned and redressed daily.

With central ECMO support, the patient received flows greater than $5.0 \mathrm{~L} / \mathrm{min}$, with $\mathrm{LV}$ venting at $1.0 \mathrm{~L} / \mathrm{min}$. The patient required a circuit exchange because of pump thrombosis on day 7 of ECMO, and subsequent attempts to anticoagulate with systemic heparin failed because of heparin resistance. Thus, on day 11 of ECMO, the patient was transitioned to an argatroban infusion $(0.02-1.02 \mu \mathrm{g} / \mathrm{kg} / \mathrm{min})$, titrated for a partial thromboplastin time of 60 to 80 seconds and an activated clotting time of 180 to 200 seconds. Lactate dehydrogenase levels were assessed at minimum every other day, and the ECMO circuit and oxygenator were invariably assessed for clots daily. The patient underwent additional circuit exchanges for pump thrombosis and postoxygenator clot formation on days 18 and 63 of ECMO, respectively.

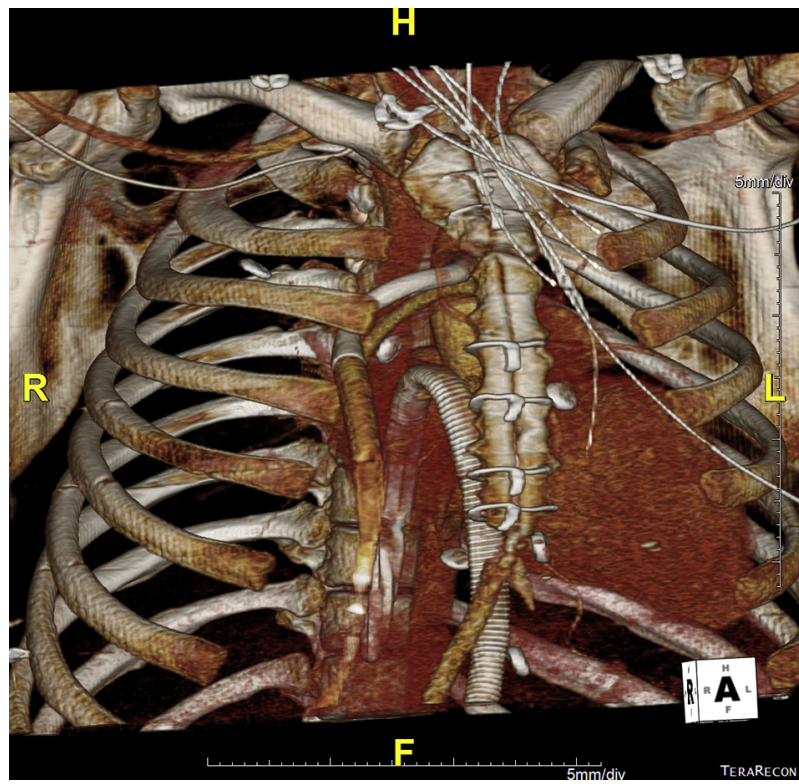

FIGURE 1. Three-dimensional virtual reality rendering of the patient's computed tomographic scan, illustrating the position of the arterial cannula entering the ascending aorta through the third intercostal space and the position of the venous cannula entering the right atrium through the subxiphoid space. $H$, Head; $R$, right; $L$, left; $F$, foot; $A$, anterior.

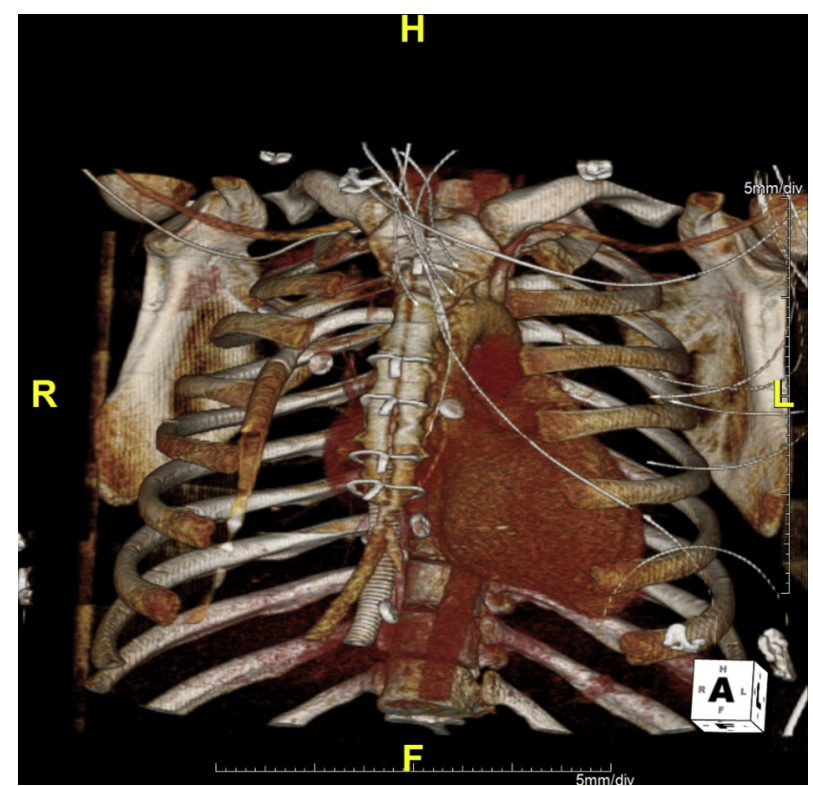

VIDEO 1. Three-dimensional virtual reality cine rendering of the patient's computed tomographic scan, illustrating the position of the arterial cannula entering the ascending aorta through the third intercostal space and the position of the venous cannula entering the right atrium through the subxiphoid space. $H$, Head; $R$, right; $L$, left; $A$, anterior; $F$, foot. Video available at: http://www.jtcvsonline.org/article/S0022-5223(18)30335-0/ fulltext.

After the operation, the patient remained in hemodynamically stable condition, and he was weaned from sedation and extubated on day 9 of ECMO. He began daily physical therapy sessions on day 13 of ECMO while remaining on full VA-ECMO support. He gradually recovered from hepatorenal dysfunction, and continuous renal replacement therapy was discontinued on day 33 of ECMO. The patient was listed for heart transplant on day 34 of ECMO. With continued physical rehabilitation during ECMO while awaiting transplant, the patient recovered ambulatory function up to 400 feet with minimal assistance, and he lost weight to a body mass index of $32.5 \mathrm{~kg} / \mathrm{m}^{2}$. On day 96 of ECMO, a brain-dead donor with the same blood type became available, and the patient was selected as the firstpriority recipient. The donor was a 33-year-old man with a good size match to the recipient (difference in height of $0 \%$; difference in body weight of $+8 \%$ ). The donor heart had normal biventricular function and was considered suitable for transplant. Our patient underwent a reoperative sternotomy and was transitioned from ECMO to full cardiopulmonary bypass. The native heart was explanted in the usual fashion. The donor heart was implanted with a standard bicaval technique. The allograft ischemic time was 247 minutes.

The patient recovered without any significant complications. Antithymocyte globulin was administered for 3 continuous days as induction of immunosuppression therapy. The 
patient also received routine immunotherapy, including tacrolimus, mycophenolate mofetil, and prednisolone. He was discharged on postoperative day 17. At the time of discharge, he did not demonstrate evidence of acute rejection. At 1 year after the transplant, the patient continues to have excellent graft function and continues his normal activities without symptomatic limitations.

\section{DISCUSSION}

Our adolescent patient was morbidly obese, presented initially with refractory cardiogenic shock, and subsequently developed liver and kidney failure. These characteristics portend a grave prognosis without treatment, but they also suggest an unfavorable outcome for both heart transplantation and ventricular assist device placement. ${ }^{2,3} \mathrm{We}$ therefore placed our patient on VA-ECMO support as bridge-to-decision therapy until he had recovered sufficiently to undergo a formal transplant evaluation. A percutaneous support strategy would have been preferable to avoid a subsequent redo sternotomy. However, our patient developed worsening liver and kidney failure despite peripheral ECMO and Impella support, and he therefore required central cannulation to attain the necessary flows. In this case, by tunneling all central ECMO cannulas away from the patient's sternum to allow sternal closure, we could awaken and extubate the patient early and begin aggressive physical therapy. We thus avoided the complications associated with prolonged mechanical ventilation and long-term sedation, and we were able to clinically optimize our patient's condition for heart transplant, not only in terms of recovering full kidney and liver function but also by strengthening his overall physical conditioning and decreasing his body weight by 80 pounds, thereby improving potential donor-recipient weight-ratios before the transplant and accelerating the course of recovery after the transplant.

Successful heart transplantation after ambulatory VAECMO remains underreported in the literature. Ambulation is risky with femorally cannulated VA-ECMO because of the life-threatening risk of dislodging or kinking the large cannulas in the groin. Subclavian artery cannulation has been reported to permit ambulatory VA-ECMO,${ }^{4}$ but our patient's critical condition necessitated central cannulation to achieve adequate support. In one case of semiambulatory VA-ECMO with central cannulation through a median sternotomy, Wong and colleagues ${ }^{5}$ reported a combined heartlung transplant for a 4-year-old child after 40 days of support. ${ }^{5}$ In our case, our strategy involved tunneling the central ECMO cannulas through the chest wall. We found that with close, daily attention to the security of the exit site sutures, our patient could safely ambulate with minimal risk of dislodging the cannulas. Furthermore, with daily cleaning of the surgical sites and the skin around the cannulas, our patient never had a wound infection during his 3 months of ECMO, and he did not receive prophylactic antibiotics.

With the immense effort of a multidisciplinary team, including heart failure surgeons, cardiologists, critical care specialists, intensive care nurses, perfusionists, and physical therapists, our 17-year-old patient had his condition successfully optimized with ambulatory VA-ECMO. $\mathrm{He}$ was successfully bridged to heart transplantion, and was discharged in good health without a prolonged postoperative recovery. Overall, this case demonstrates that our transthoracic tunneling technique for ambulatory central VA-ECMO is a safe and effective method of bridging select patients to heart transplantion.

\section{References}

1. Lehr CJ, Zaas DW, Cheifetz IM, Turner DA. Ambulatory extracorporeal membrane oxygenation as a bridge to lung transplantation: walking while waiting. Chest. 2015;147:1213-8.

2. Boucek MM, Aurora P, Edwards LB, Taylor DO, Trulock EP, Christie J, et al. Reg istry of the International Society for Heart and Lung Transplantation: tenth official pediatric heart transplantation report-2007. J Heart Lung Transplant. 2007;26: 796-807.

3. Matthews JC, Pagani FD, Haft JW, Koelling TM, Naftel DC, Aaronson KD. Model of end-stage liver disease score predicts left ventricular assist device operative transfusion requirements, morbidity, and mortality. Circulation. 2010;121:214-20.

4. Javidfar J, Brodie D, Costa J, Miller J, Jurrado J, LaVelle M, et al. Subclavian artery cannulation for venoarterial extracorporeal membrane oxygenation. ASAIO J. 2012;58:494-8.

5. Wong JY, Buchholz H, Ryerson L, Conradi A, Adatia I, Dyck J, et al. Successful semi-ambulatory veno-arterial extracorporeal membrane oxygenation bridge to heart-lung transplantation in a very small child. Am J Transplant. 2015;15: 2256-60. 